\title{
Unified Power Flow Controller for Non-Linear Loads Using Adaptive Power Quality Theory
}

\author{
Jaya Raju Gaddala \\ Electrical and Electronic Engineering, University College of Engineering \& Technology \\ Acharya Nagarjuna University, Nagarjuna Nagar, Guntur - 522 510, Andhra Pradesh, India \\ jayaraju2006@gmail.com
}

\section{Sambasiva Rao Gudapati}

Department of Electrical \& Electronics Engineering, R.V.R. \& J.C. College of Engineering, Guntur - 522 019, Andhra Pradesh sambasiva.gudapati@gmail.com

\begin{abstract}
Harmonics reduction techniques in source current were found to be unreliable and imbalanced with different load conditions. This certain unreliability problem in harmonics mitigation is caused by non-linear loads. The harmonics and power quality problems are eliminated by filters. These filters are expensive to provide a dynamic response under various load conditions. The new unified power flow controller composed of a series and shunt compensator provides more secured power systems and good voltage stability at various load conditions. $D-Q$ theory is used to generate the reference current from the AC source current. $D-Q$ theory produces sinusoidal harmonics that are opposite to load harmonics. This UPFC can absorb or inject reactive power in the PCC. D-Q theory followed by a hysteresis current controller generates PWM pulses to the shunt and series compensator. The PI and fuzzy logic controllers preserve the DC link voltage in the storage capacitor. The proposed technique has been simulated by using Matlab simulation under different load conditions.
\end{abstract}

Keywords - D-Q (direct-quadrature) theory, PWM (pulse-width modulation), series compensator, shunt compensator, UPFC (unified power flow controller)

\section{INTRODUCTION}

The power quality problems in the distribution and generation system are due to non-linear loads, which is a matter of important concern. These power quality problems heavily damage the source generator. In recent days, power electronic devices with active and passive power compensation are used to overcome these power quality issues. The reactive power problems are compensated by flexible AC transmission system (FACTS) devices. If the power quality issues were not solved, then this would affect the stability of the power system. In order to mitigate these power quality problems, a shunt active power filter is used [1]. With this type of filter only source current compensation is achieved. Synchronous reference frame theory is used for generating reference current and source current harmonic reduction. But these types of shunt active power filters cannot be used for voltage compensation. These drawbacks are overcome by the static synchronous compensator (STATCOM) [2]. High voltage stress is produced by the three-phase voltage source inverter (VSI) in a shunt active filter. However, by means of the static synchronous compensator such voltage stress can be reduced by using external DC sources [3]. The solution to improve the power quality at the load side is of great importance when the production processes get more complicated and which includes providing energy without interruption require a higher liability level, without harmonic distortion and with tension regulation between very narrow margins [4]. A photovoltaic (PV) based static synchronous compensator (STATCOM) reduces voltage stress in the three-phase voltage source inverter (VSI). But only source current compensation is possible with static synchronous compensator (STATCOM) devices.

These drawbacks of the static synchronous compensator (STATCOM) and the shunt active power filter are overcome by a new unified power flow controller (UPFC), which consists of the series and the shunt compensator [5] to regulate load voltage and to preserve sinusoidal grid current at the unit power factor at the same time. A unified power flow controller (UPFC) is recognized as the most versatile and complex device among all (Flexible AC Transmission System ) FACTS devices as reference pulse generation is the major task in 
a unified power flow controller. The unified power flow controller consisting of two multifunctional voltage source converters (VSC) whose primary function is to control the power flow and secondary functions is voltage regulation. The unified power flow controller with reference current generation techniques [6] reduces most of the source current harmonics better than the above two methods. But, DC link voltage control techniques were not used; hence voltage stability problems increased. In [7] and [8], the unified power flow controller is utilized for reactive power compensation with synchronous reference frame (SRF) theory and the power swing characteristics are followed by current control theories, but the main drawback of this system is uncompensated DC voltage. This drawback may be overcome by the proposed research idea.

The reference current is generated from the source voltage and current using direct-quadrature (D-Q) theory. The DC link voltage is controlled by using PI and fuzzy logic based controllers. In [9], a fuzzy logic controller is proposed to overcome the problems of the existing unified power flow controllers (UPFC) and it provides dynamic power flow control in transmission lines. To produce a relatively fast response and hence to reduce the interaction between real and reactive power flows, a control scheme for a unified power flow controller based on $d-q$ axis theory was developed, where the cross-coupling controller using $d-q$ axis theory was applied to both the series and the shunt converter of the unified power flow controller. The principle of cross-coupling controller is such that the q-axis voltage Vq controls the $d$-axis current Id and the $\mathrm{d}$-axis voltage $\mathrm{Vd}$ controls the $\mathrm{q}$ axis current lq, thereby controlling both real and reactive powers independently.

The D-axis control system controls the DC link capacitor voltage and the Q-axis control system controls the UPFC bus voltage. Two fuzzy controllers have been implemented to obtain the $\mathrm{D}$ and $\mathrm{Q}$ reference values of the shunt current. Then the measured values of the shunt current are compared with the obtained reference values and sent to the PI controller. The output of the PI (proportional integral) controllers are D and Q components of the shunt voltage used to determine the magnitude and phase angle of the injected voltage by the shunt converter. The transmission line real power flow is controlled by injecting a component of the series voltage in quadrature with the UPFC bus voltage obtained from the difference between the reference and the measured real power passed through a fuzzy logic controller block. The transmission line reactive power is controlled by modulating the transmission line side bus voltage reference. The transmission line side bus voltage is controlled by injecting a component of the series voltage in-phase with the UPFC bus voltage. The $\mathrm{D}$ and $\mathrm{Q}$ components of series injected voltage have been used to determine the magnitude and phase angle of the series converter.

\section{PROPOSED UPFC SYSTEM DESIGN}

The UPFC system consists of two converters, namely the SSSC (Static Synchronous Series Compensator) and the STATCOM (Static Synchronous Compensator)

The series compensator is linked in series with the transmission line using a series transformer. This converter converts $A C$ voltage into $D C$ voltage and this voltage is stored in the capacitor. The shunt converter converts stored DC voltage into three-phase alternating voltage. This voltage is fed into non-linear load through the transformer. D-Q theory generates the reference current from input source voltage and current. The hysteresis current controller compares the actual and the reference current to produce a PWM pulse. This pulse is fed into the shunt converter.

Similarly, reference voltage and actual voltages are compared and the error is PWM pulses. These pulses are fed into the series converter. The PI controller and fuzzy logic controllers maintain constant DC voltage in the capacitor with the help of the series converter. Figure 1 shows the UPFC block diagram. Here, the UPFC works by voltage control mode. This UPFC system achieves both voltage and current compensation, i.e., it does both shunt and series compensator work. Opposite harmonics are injected in the PCC through the shunt converter..

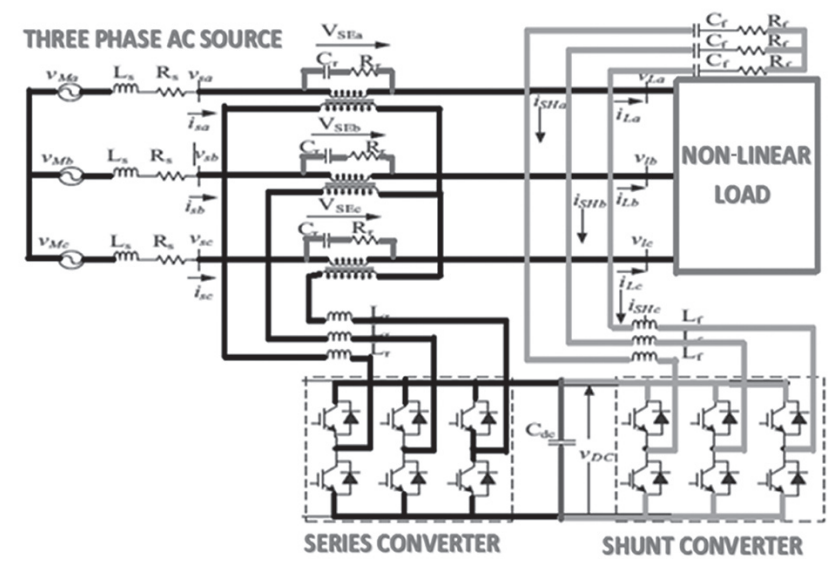

Fig. 1. Proposed UPFC schematic diagram 


\section{PROPOSED D-Q THEORY MODELING FOR UPFC SYSTEM}

Figure 2 shows D-Q theory modeling for the proposed UPFC system.

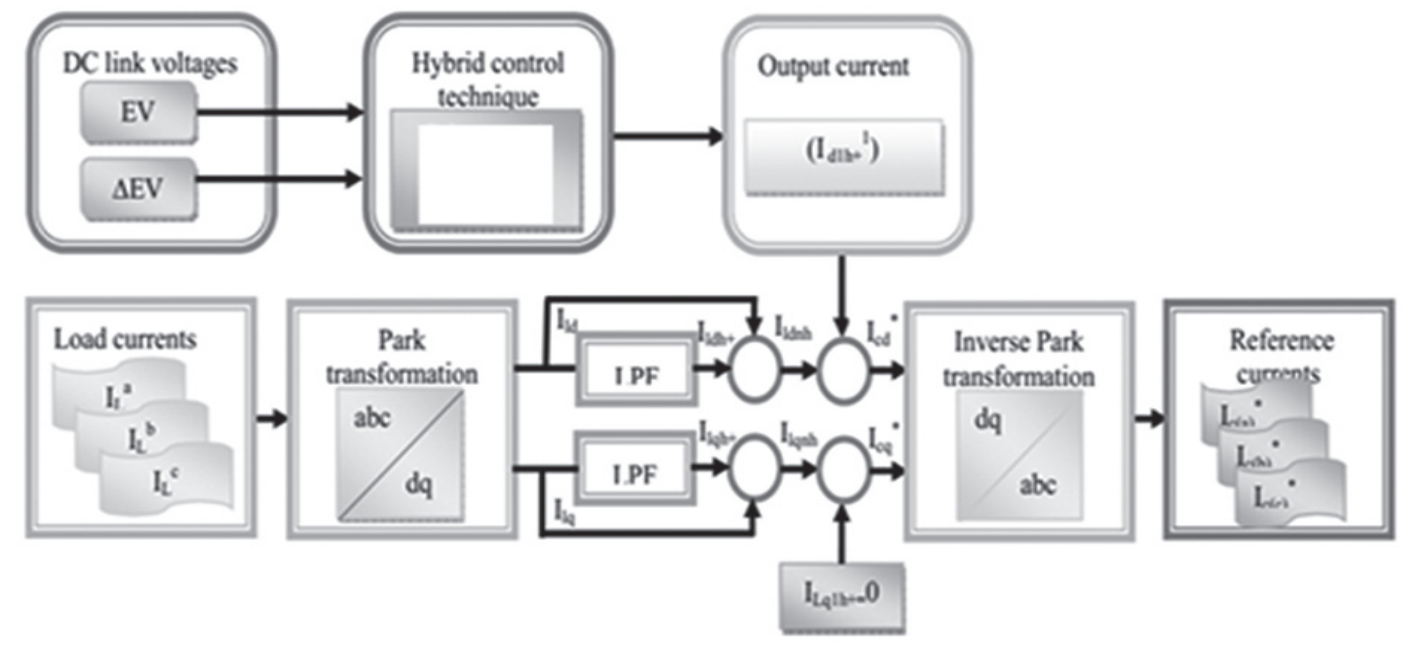

Fig. 2. D-Q theory modeling for the UPFC system

Three-phase AC voltage has been separated into three components, namely positive, negative and zero sequence elements.

$$
\begin{aligned}
& {\left[\begin{array}{l}
V_{s a} \\
V_{s b} \\
V_{s c}
\end{array}\right]=V_{a}\left[\begin{array}{l}
\cos \left(\omega t+\varphi_{0}\right) \\
\cos \left(\omega t+\varphi_{0}\right) \\
\cos \left(\omega t+\varphi_{0}\right)
\end{array}\right]+V_{b}\left[\begin{array}{c}
\cos \left(\omega t+\varphi_{1}\right) \\
\cos \left(\omega t-\frac{2 \pi}{3}+\varphi_{1}\right) \\
\cos \left(\omega t+\frac{2 \pi}{3}+\varphi_{1}\right)
\end{array}\right]+} \\
& \mathrm{V}_{\mathrm{c}}\left[\begin{array}{c}
\cos \left(\omega \mathrm{t}+\varphi_{2}\right) \\
\cos \left(\omega \mathrm{t}+\frac{2 \pi}{3}+\varphi_{2}\right) \\
\cos \left(\omega \mathrm{t}-\frac{2 \pi}{3}+\varphi_{2}\right)
\end{array}\right]
\end{aligned}
$$

where $V_{s a^{\prime}} V_{s b^{\prime}}, V_{s}$ are three-phase AC voltages, whereas $V_{a^{\prime}} V_{b^{\prime}}, V_{c}$ are zero, positive and negative sequence voltages, respectively.

$$
\mathrm{V}_{\mathrm{s}}=\left[\begin{array}{c}
\mathrm{V}_{\mathrm{sa}} \\
\mathrm{V}_{\mathrm{sb}} \\
\mathrm{V}_{\mathrm{sc}}
\end{array}\right]=\left[\begin{array}{c}
\mathrm{V}_{\mathrm{a} 0} \\
\mathrm{~V}_{\mathrm{b} 0} \\
\mathrm{~V}_{\mathrm{c} 0}
\end{array}\right]+\left[\begin{array}{c}
\mathrm{V}_{\mathrm{a} 1} \\
\mathrm{~V}_{\mathrm{b} 1} \\
\mathrm{~V}_{\mathrm{c} 1}
\end{array}\right]+\left[\begin{array}{c}
\mathrm{V}_{\mathrm{a} 2} \\
\mathrm{~V}_{\mathrm{b} 2} \\
\mathrm{~V}_{\mathrm{c} 2}
\end{array}\right]
$$

Three-phase source current is represented as follows:

$$
\mathrm{I}_{\mathrm{s}}=\left[\begin{array}{c}
\mathrm{I}_{\mathrm{sa}} \\
\mathrm{I}_{\mathrm{sb}} \\
\mathrm{I}_{\mathrm{sc}}
\end{array}\right]=\left[\begin{array}{c}
\mathrm{I}_{\mathrm{a} 0} \\
\mathrm{I}_{\mathrm{b} 0} \\
\mathrm{I}_{\mathrm{c} 0}
\end{array}\right]+\left[\begin{array}{l}
\mathrm{I}_{\mathrm{a} 1} \\
\mathrm{I}_{\mathrm{b} 1} \\
\mathrm{I}_{\mathrm{c} 1}
\end{array}\right]+\left[\begin{array}{l}
\mathrm{I}_{\mathrm{a} 2} \\
\mathrm{I}_{\mathrm{b} 2} \\
\mathrm{I}_{\mathrm{c} 2}
\end{array}\right]
$$

Apparent power is given as:

$$
S_{s}=P_{s}+j Q_{s}=V_{s} I_{s}^{*}
$$

The $\mathrm{D}-\mathrm{Q}$ theory general equation is given as:

$$
\mathrm{S}_{\mathrm{s} 012}=\mathrm{S}_{1012}+\mathrm{S}_{\mathrm{f} 012}
$$

0,1 , and 2 represent zero, positive and negative sequence powers, respectively, and the total power injected to the grid is calculated as:

$$
\begin{aligned}
& \mathrm{S}_{\mathrm{l} 012}=\mathrm{S}_{\mathrm{s} 012}+\mathrm{S}_{\mathrm{h} 012} \\
& \mathrm{~S}_{\mathrm{l012}}=\mathrm{p}_{\mathrm{s} 012}(\mathrm{t})+\mathrm{Q}_{\mathrm{s} 012}(\mathrm{t})+\mathrm{p}_{\mathrm{h} 012}(\mathrm{t})+\mathrm{Q}_{\mathrm{h} 012}(\mathrm{t})
\end{aligned}
$$

The terms $\mathrm{P}$ and $\mathrm{Q}$ term represent real and reactive power of the transmission system, respectively.

Input three-phase voltage and currents are transformed to a $\beta 0$ parameters by using Clarke transformation.

$$
\begin{aligned}
& \mathrm{V}_{\mathrm{a} \beta 0}=\frac{2}{3}\left[\begin{array}{ccc}
1 & -\frac{1}{2} & -\frac{1}{2} \\
0 & \frac{\sqrt{3}}{2} & -\frac{\sqrt{3}}{2} \\
\frac{1}{2} & \frac{1}{2} & \frac{1}{2}
\end{array}\right] \mathrm{V}_{\mathrm{s}} \\
& \mathrm{I}_{\mathrm{a} \beta 0}=\frac{2}{3}\left[\begin{array}{ccc}
1 & -\frac{1}{2} & -\frac{1}{2} \\
0 & \frac{\sqrt{3}}{2} & -\frac{\sqrt{3}}{2} \\
\frac{1}{2} & \frac{1}{2} & \frac{1}{2}
\end{array}\right] \mathrm{I}_{\mathrm{S}}
\end{aligned}
$$

$a \beta$ and parameters are calculated from the above equations.

$$
\begin{aligned}
& V_{\alpha \beta}=\frac{2}{3}\left[\begin{array}{ccc}
1 & -\frac{1}{2} & -\frac{1}{2} \\
0 & \frac{\sqrt{3}}{2} & -\frac{\sqrt{3}}{2}
\end{array}\right] V_{s} \\
& I_{\alpha \beta}=\frac{2}{3}\left[\begin{array}{ccc}
1 & -\frac{1}{2} & -\frac{1}{2} \\
0 & \frac{\sqrt{3}}{2} & -\frac{\sqrt{3}}{2}
\end{array}\right] I_{s}
\end{aligned}
$$

From the positive and negative sequence elements $a \beta$ and parameters are calculated.

$$
\mathrm{V}_{\mathrm{\alpha} \beta}=\mathrm{V}_{1}\left[\begin{array}{c}
\cos \left(\omega \mathrm{t}+\varphi_{1}\right) \\
\sin \left(\omega \mathrm{t}+\varphi_{1}\right)
\end{array}\right]+\mathrm{V}_{2}\left[\begin{array}{c}
\cos \left(-\omega \mathrm{t}+\varphi_{2}\right) \\
\sin \left(-\omega \mathrm{t}+\varphi_{2}\right)
\end{array}\right]
$$




$$
\begin{gathered}
\mathrm{V}_{\mathrm{dq} 1}=\mathrm{V}_{\mathrm{a} \beta}\left[\begin{array}{cc}
\cos (\omega \mathrm{t}) & \sin (\omega \mathrm{t}) \\
-\sin (\omega \mathrm{t}) & \cos (\omega \mathrm{t})
\end{array}\right] \\
\mathrm{V}_{\mathrm{dq} 2}=\mathrm{V}_{\mathrm{a} \beta}\left[\begin{array}{cc}
-\cos (\omega \mathrm{t}) & -\sin (\omega \mathrm{t}) \\
\sin (\omega \mathrm{t}) & -\cos (\omega \mathrm{t})
\end{array}\right] \\
\mathrm{V}_{\mathrm{dq} 1}=\mathrm{V}_{1}\left[\begin{array}{l}
\cos \left(\varphi_{1}\right) \\
\sin \left(\varphi_{1}\right)
\end{array}\right]+\mathrm{V}_{2}\left[\begin{array}{ll}
\cos \left(\varphi_{2}\right) & \sin \left(\varphi_{2}\right) \\
-\sin \left(\varphi_{2}\right) & \cos \left(\varphi_{2}\right)
\end{array}\right]\left[\begin{array}{l}
\cos (2 \omega \mathrm{t}) \\
\sin (2 \omega \mathrm{t})
\end{array}\right]
\end{gathered}
$$

$$
\mathrm{V}_{\mathrm{dq} 1}=\mathrm{V}_{1}\left[\begin{array}{c}
\cos \left(\varphi_{1}\right) \\
\sin \left(\varphi_{1}\right)
\end{array}\right]+\mathrm{V}_{\mathrm{d} 2}\left[\begin{array}{c}
\cos (2 \omega \mathrm{t}) \\
-\sin (2 \omega \mathrm{t})
\end{array}\right]+\mathrm{V}_{\mathrm{q} 2}\left[\begin{array}{c}
\sin (2 \omega \mathrm{t}) \\
\cos (2 \omega \mathrm{t})
\end{array}\right]
$$

$$
\mathrm{V}_{\mathrm{dq} 2}=\mathrm{V}_{2}\left[\begin{array}{c}
\cos \left(\varphi_{2}\right) \\
\sin \left(\varphi_{2}\right)
\end{array}\right]-\mathrm{V}_{\mathrm{d} 1}\left[\begin{array}{c}
\cos (2 \omega \mathrm{t}) \\
\sin (2 \omega \mathrm{t})
\end{array}\right]+\mathrm{V}_{\mathrm{q} 1}\left[\begin{array}{c}
\sin (2 \omega \mathrm{t}) \\
-\cos (2 \omega \mathrm{t})
\end{array}\right]
$$

The reference signal from $D-Q$ theories is calculated for UPFC as follows:

$$
\begin{gathered}
\mathrm{P}_{0}=\frac{3}{2}\left[\begin{array}{llll}
\mathrm{v}_{\mathrm{d} 1} & -\mathrm{v}_{\mathrm{q} 1} & -\mathrm{v}_{\mathrm{d} 2} & \mathrm{v}_{\mathrm{q} 2}
\end{array}\right]\left[\begin{array}{l}
\mathrm{i}_{\mathrm{q} 2} \\
\mathrm{i}_{\mathrm{d} 2} \\
\mathrm{i}_{\mathrm{q} 1} \\
\mathrm{i}_{\mathrm{d} 1}
\end{array}\right] \\
\mathrm{Q}_{0}=\mathrm{P}_{2}=\frac{3}{2}\left[\begin{array}{llll}
\mathrm{v}_{\mathrm{d} 1} & \mathrm{v}_{\mathrm{q} 1} & \mathrm{v}_{\mathrm{d} 2} & \mathrm{v}_{\mathrm{q} 2}
\end{array}\right]\left[\begin{array}{l}
\mathrm{i}_{\mathrm{d} 2} \\
\mathrm{i}_{\mathrm{q} 2} \\
\mathrm{i}_{\mathrm{d} 1} \\
\mathrm{i}_{\mathrm{q} 1}
\end{array}\right]
\end{gathered}
$$

The reference signals from source voltage and currents are extracted by using Park and Clarke transformations. These reference signals are compared with the actual value by means of a hysteresis comparator. The output of the hysteresis current controller are PWM pulses, which are fed into the series and the shunt converter. PI and fuzzy logic controllers maintain DC link voltage at a constant value. The proposed system results are validated using MATLAB simulation.

The function of the DC voltage controller is to monitor the actual Vdc across the capacitor and compute the error as the difference between the actual Vdc and the set Vdc. This error is fed as input into the PI controller, where the deviation in the DC voltage is calculated. The output of the PI controller is treated as the reference for the real component of current drawn by UPFC. These two reference quantities are compared with the actual quantities in a cross-coupled controller. Thus capacitor voltage is tracked and maintained as a constant by using a PI controller.

The fuzzy logic block consists of two inputs and one output. The first input is the error and the other input is a rate of error which is one sampling before error values. For all transmission line parameters, input and output membership functions are named similarly. The FL controller consists of 3 steps, namely fuzzification, the rule base system and defuzzification. Here, fuzzification is carried out through the slope equation. All membership functions of FL controllers consist of triangular based membership functions as they provide smooth control. Fuzzy based input and output membership functions are formed by using a 1-D array. Defuzzification is carried out through a weighted average to convert the fuzzy linguistic variable into real crisp values. The main use of the fuzzy control system is its effective dependency on empirical rules. Fuzzy systems are easily enhanced by including new rules or new features to improve their performance. Fuzzy control is used to improve the existing control systems by adding a layer of intelligence to the current control method.

\section{SIMULATION RESULTS AND DISCUSSION}

The proposed UPFC work is implemented by using Matlab simulation and the shunt and series converter is developed by the IGBT device. This system is developed with $100 \mathrm{~V} \mathrm{AC}$ and this source voltage is given to the non-linear load. In this system, a diode bridge rectifier and inductive loads are used as best non-linear loads. This non-linear load causes heavy harmonics in the source current, the proposed UPFC system reduces the harmonics and maintains the stability in the power system.

Figure 3 shows a three-phase AC voltage waveform. For testing under different voltage conditions the source voltage has dropped from 0.4 to $0.6 \mathrm{sec}$. At this time, our proposed UPFC maintains voltage stability in order to prove voltage compensation.

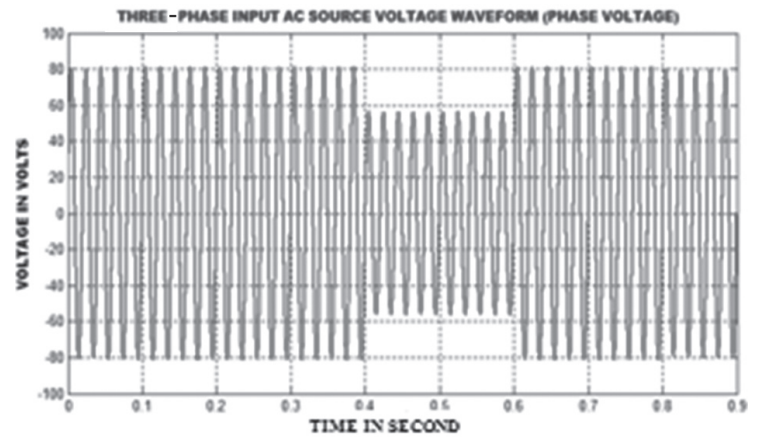

Fig. 3. Input source voltage with a non-linear load

Figure 4 shows an AC source current waveform, which has higher order harmonics, but the UPFC system reduces the source current harmonics.

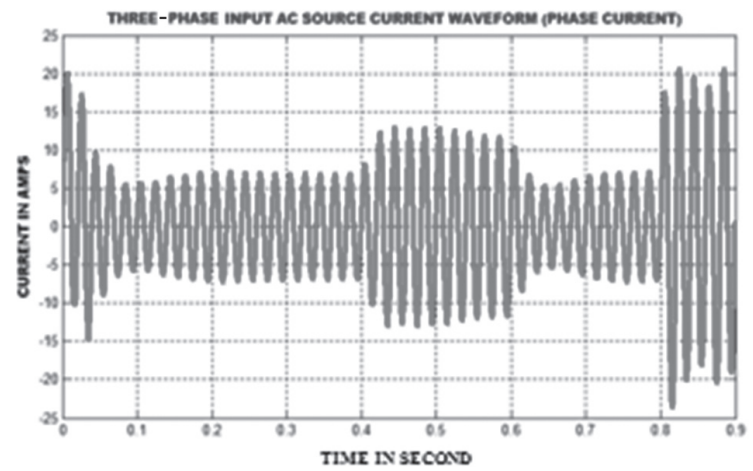

Fig. 4. Input source current waveform with a nonlinear load 
Three-phase AC voltage is fed into the non-linear load. The UPFC maintains constant voltage to the load as fixed sufficient voltage is available from the DC link capacitor.

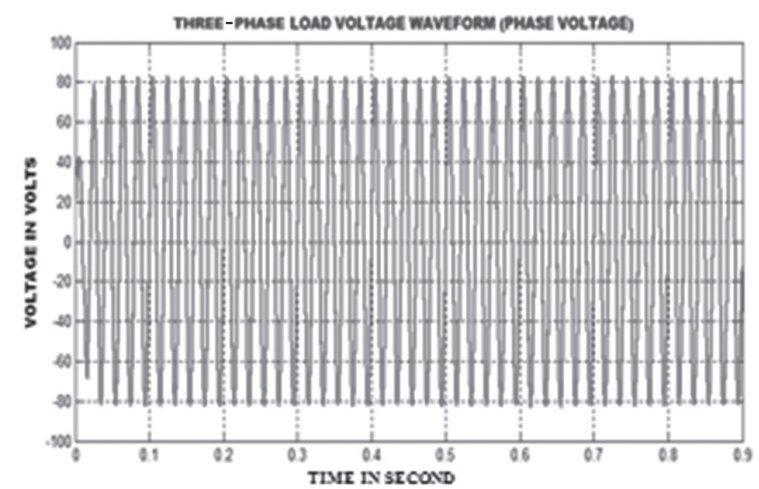

Fig. 5. Load voltage waveform using the UPFC system

Figure 6 shows a sinusoidal load current waveform after the harmonics are reduced by the shunt converter in the load and source side.

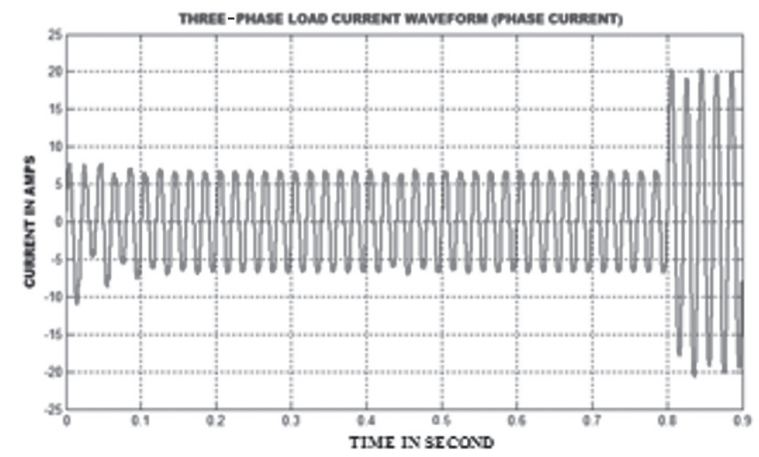

Fig. 6. Load current waveform using the UPFC system

Figure 7 shows a DC link capacitor voltage waveform. The series converter using the PWM technique maintains constant DC voltage. With this voltage the shunt converter can provide voltage stable operation to the load.

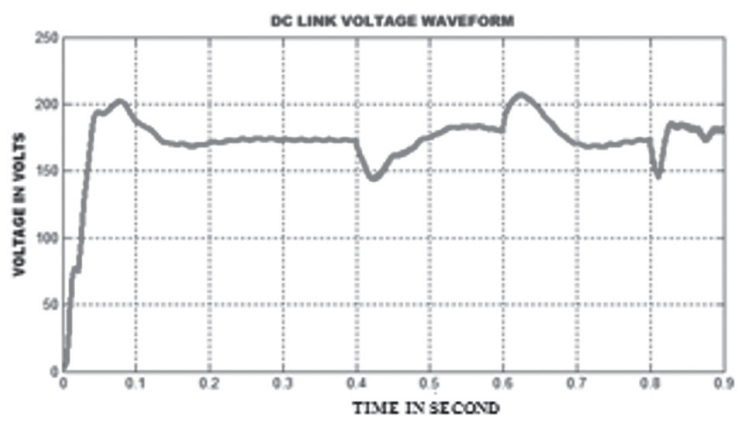

Fig. 7. DC link voltage waveform using PI and fuzzy logic controllers

The UPFC system increases active power and reduces reactive power. Active and reactive powers at the source side, the load side, the series converter and the shunt converter, are shown in the following figures, respectively.

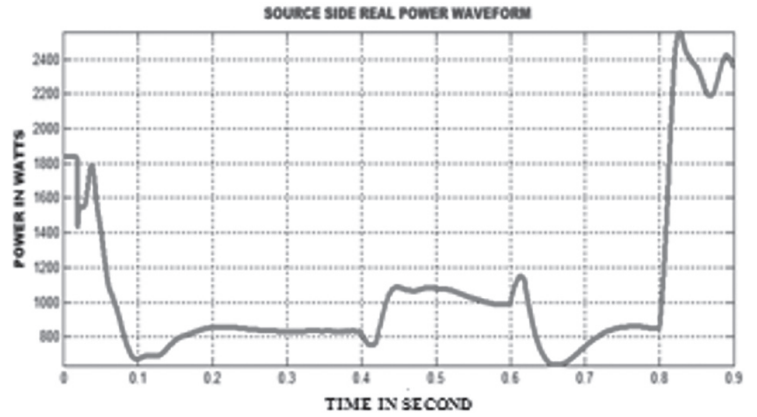

Fig. 8. Input source side real power waveform

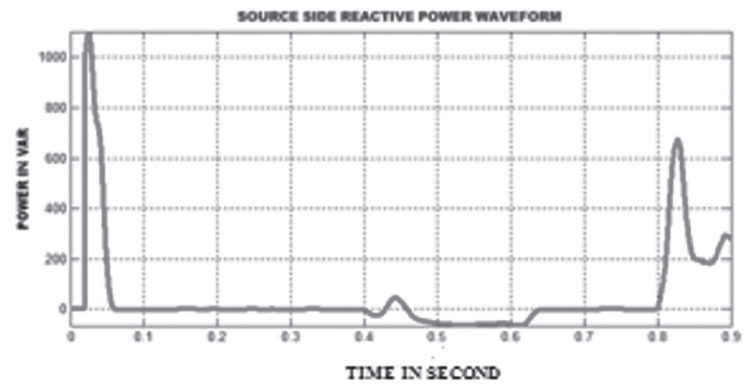

Fig. 9. Input source side reactive power waveform

Figures 10 and 11 show the load side real and reactive power waveforms, respectively. The UPFC system reduces reactive power with good power quality.

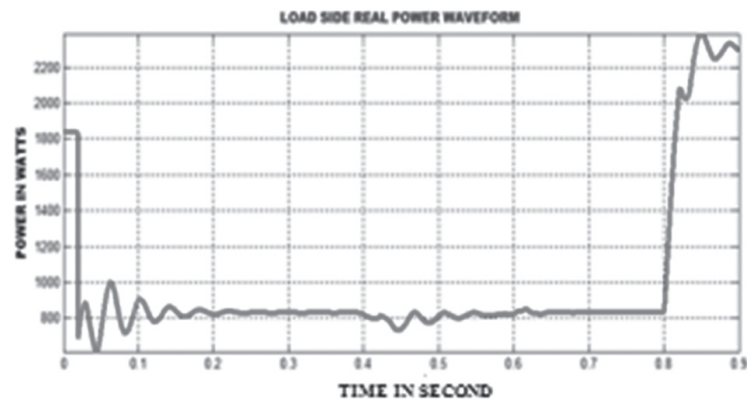

Fig. 10. Load side real power waveform with a nonlinear load

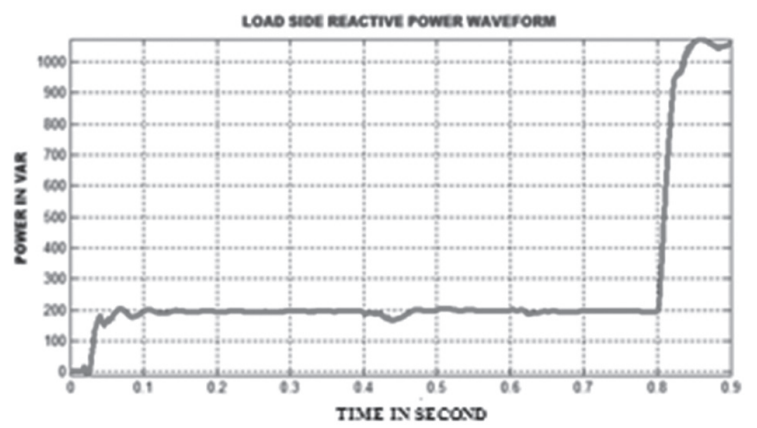

Fig. 11. Load side real power waveform with a nonlinear load 
While increasing reactive power of the transmission system due to a non-linear load, the series converter absorbs the power from the PCC and it is backed up in the DC link capacitor.

In the meantime, the shunt converter injects active power in the PCC through the shunt transformer.

Figures 12 and 13 show the series and shunt converter power waveforms, respectively.

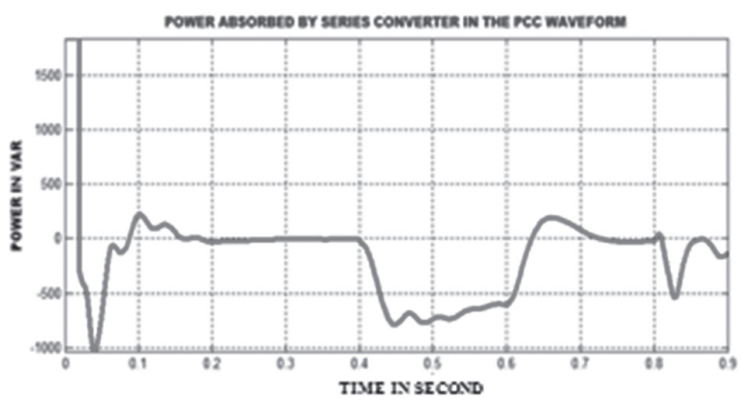

Fig. 12. Series converter absorbed power waveform in UPFC

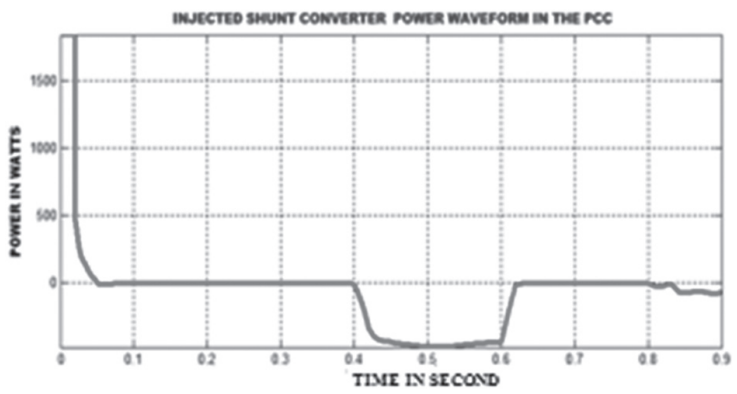

Fig. 13. Shunt converter injected power waveform in the PCC

Figure 14 shows a reference voltage from the source side using $\mathrm{D}-\mathrm{Q}$ theories.

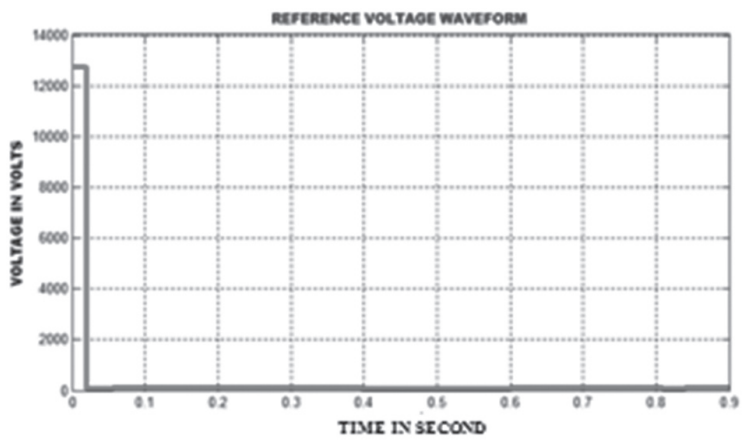

Fig. 14. Reference voltage for PWM generation in the series converter

A D-Q theory based UPFC system reduces source current harmonics and current harmonics should obey the IEEE512 power quality standard. Figure 15 shows the source current THD waveform.

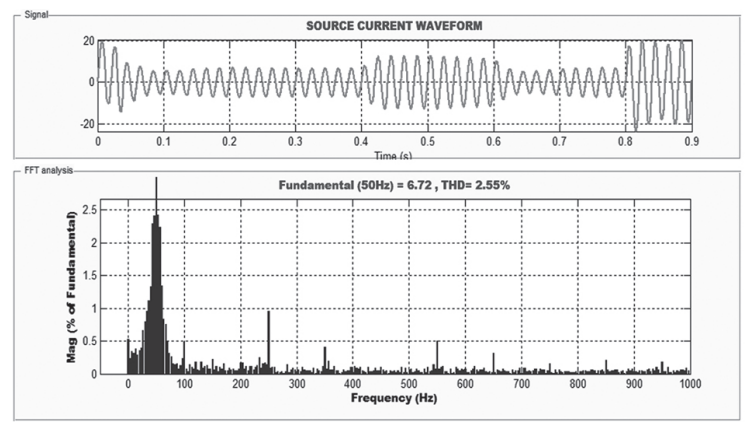

Fig. 15. Input source current THD waveform using FFT analysis

\section{CONCLUSIONS}

D-Q mathematical models for a unified power flow controller have been simulated by MATLAB. Unbalanced input voltage with a different non-linear load is tested in this paper. The DC link voltage is maintained constant by using PI and fuzzy logic based controllers. This reduces reactive power problems and increases active power. The series converter absorbs reactive power and the shunt converter injects power in the PCC, i.e. both voltage injection and absorption takes place due to this UPFC. Source current harmonics are reduced by using $\mathrm{D}-\mathrm{Q}$ theories. This minimizes source current harmonics by $2.55 \%$. Its performance is satisfactory in a normal working environment with a fast frequency response. It is also proved to be the most reliable method with harmonic values that are less than the IEEE standard.

However, certain modifications and developments can be carried out to implement a complex control system which involves intensive computational calculations. But optimization techniques such as artificial neural networks or a genetic algorithm can be studied to reduce the mathematical implementation in the design of a complex controller.

\section{REFERENCES:}

[1] W. U. K. Tareen, S. Mekhielf, "Three-Phase Transformerless Shunt Active Power Filter with Reduced Switch Count for Harmonic Compensation in Grid-Connected Applications", IEEE Transactions on Power Electronics, Vol. 33, No. 6, 2018, pp. 48684881.

[2] R. K. Varma, E. M. Siavashi, "PV-STATCOM: A New Smart Inverter for Voltage Control in Distribution Systems", IEEE Transactions on Sustainable Energy, Vol. 9, No. 4, 2018, pp. 1681-1691.

[3] L. Wang, C.-S. Lam, M.-C. Wong, “A Hybrid-STATCOM with Wide Compensation Range and Low DC-Link Voltage", IEEE Transactions on Industrial Electronics, Vol. 63, No. 6, 2016, pp. 3333-3343. 
[4] E. Gholipur, S. Saadate, "Improving of Transient Stability is Power Systems Using UPFC", IEEE Transactions on Power Delivery, Vol. 20, No. 2, 2005, pp. 1677-1682.

[5] H. Liu, X. Li, G. Qin, S. Hao, "Stability of grid connected system of two types of wind turbines with UPFC", The Journal of Engineering, Vol, 2017, No. 13, 2017, pp. 2178-2183.

[6] A. Mohanty, S. Patra, P. K. Ray, "Robust fuzzy-sliding mode based UPFC controller for transient stability analysis in autonomous wind-diesel-PV hybrid system", IET Generation, Transmission \& Distribution, Vol. 10, No. 5, 2016, pp. 1248-1257.
[7] U. Malhotra, R. Gokaraju, "An Add-On Self-Tuning Control System for a UPFC Application", IEEE Transactions on Industrial Electronics, Vol. 61, No. 5, 2014, pp. 2378-2388.

[8] F. Z. Peng, Y. Liu, S. Yang, S. Zhang, D. Gunasekaran, U. Karki, "Transformer-Less Unified Power-Flow Controller Using the Cascade Multilevel Inverter", IEEE Transactions on Power Electronics, Vol. 31, No. 8, 2016, pp. 5461-5472.

[9] F. M. Albatsh, S. Mekhilef, S. Ahmad, H. Mokhlis, "Fuzzy-Logic-Based UPFC and Laboratory Prototype Validation for Dynamic Power Flow Control in Transmission Lines", IEEE Transactions on Industrial Electronics, Vol. 64, No. 12, 2017, pp. 9538-9548. 